\title{
SEQUÍA, AGUA Y CAMBIO CLIMÁTICO. PERCEPCIÓN "us SOCIAL, OPINIÓN PÚBLICA Y VALORACIÓN DE MÉDIDÁS DE GESTIÓN
}

Pilar Paneque, Regina Lafuente, Jesús Vargas y Ruth Pérez

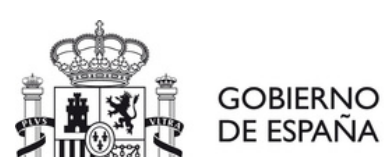

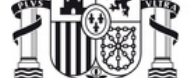
FECYT $\xi \circ$
Observatorio Ciudadano de la Sequía Citizen Observatory of Drought

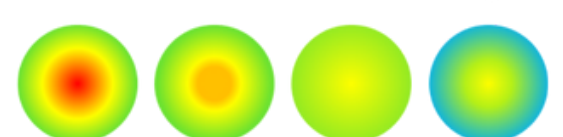


Observatorio Ciudadano de la Sequía

Citizen Observatory of Drought

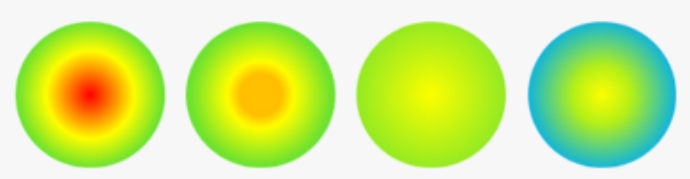

\section{CON LA COLABORACIÓN DE}

la Fundación Española para la Ciencia y la Tecnología - Ministerio de Ciencia e Innovación

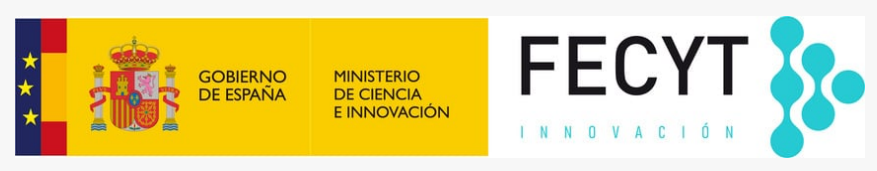

\section{Autoria}

Pilar Paneque (contacto principal)

ppansal@upo.es

Regina Lafuente

rlafuente@iesa.csic.es

Jesús Vargas

jvarmol@upo.es

Ruth Pérez

rperezlazaro@gmail.com

\section{Diseño y maquetación}

Amaranta Heredia Jaén

aherjae@upo.es

\section{D) $10.46661 /$ rio. 11700}

\section{AGRADECIMIENTOS}

Agradecemos su colaboración a todo el equipo del Observatorio Ciudadano de la Sequía.

Citar como: Paneque, P., Lafuente, R., Vargas, J., \& Pérez, R. (2021). Sequía, agua y cambio climático. Percepción social, opinión pública y valoración de medidas de gestión. Observatorio Ciudadano de la Sequía. https://dx.doi.org/10.46661/rio.11700
Para cualquier consulta, no dude en ponerse en contacto con el equipo.

\section{Contacto}

https://observasequia.es/ ocsequia@gmail.com @ObserCiudSequia 


\section{SEQUÍA, AGUA Y CAMBIO CLIMÁTICO. PERCEPCION SOCIAL, OPINION PUBLICA Y VALORACION DE MEDIDAS DE GESTIÓN}

\section{Pilar Paneque, Regina Lafuente, Jesús Vargas y Ruth Pérez}

\section{Presentación}

El Observatorio Ciudadano de la Sequía es un proyecto de ciencia ciudadana financiado por la Fundación Española para la Ciencia y Tecnología (FECYT) que persigue avanzar en el mejor conocimiento del riesgo de sequía en España, para lo cual propone, entre otros objetivos, la construcción de un índice de vulnerabilidad a dicho riesgo que incorpora indicadores socio-institucionales, que han sido menos ensayados hasta el momento, y la deliberación sobre distintas medidas de gestión.

En particular, tres de los dieciséis indicadores integrados en el citado índice de vulnerabilidad se construyen a partir de las respuestas a un cuestionario alojado en el portal desarrollado en el marco del proyecto (https://observasequia.es/), que incluye además preguntas sobre el conocimiento del reparto del agua y las preferencias por medidas de gestión del agua y de la sequía. En este portal se facilita además a los ciudadanos la consulta de información a través de un geovisor web que permite visualizar información hidrológica, climática, sobre planificación y gestión de sequías y sobre el grado de vulnerabilidad de cada territorio, así como la solución de dudas terminológicas e información municipal a través de un chatbot conversacional.
Este informe presenta los principales resultados obtenidos en la realización del cuestionario durante los meses comprendidos entre mayo y septiembre de 2021. Con su publicación, el Observatorio Ciudadano de la Sequía responde al compromiso de divulgación científica y aspira a que su difusión tenga un impacto favorable entre los actores responsables de la gestión de los recursos hídricos, desde el convencimiento de que para obtener resultados eficaces $y$ sostenibles se debe realizar una evaluación de distintas alternativas de gestión de los recursos hídricos que incluya la valoración del grado de aceptación social de las medidas contempladas.

\section{Antecedentes}

Los miembros del equipo del Observatorio Ciudadano de la Sequía han realizado avances en relación con el estudio de los modelos de gestión del agua y de la sequía y con las resistencias existentes para realizar una transición hidrológica hacia nuevas formas de gestión (Lafuente et al., 2018, 2020, 2021; Paneque, 2015; Paneque et al., 2018; Paneque \& Vargas, 2015; Vargas \& Paneque, 2017, 2019; Vargas et al., 2021). En estos estudios, el análisis de la opinión pública ha resultado fundamental para detectar las debilidades de la información que los ciudadanos manejan sobre el uso del agua y sus implicaciones en la comprensión de la percepción de los riesgos y el apoyo social a estrategias alejadas de la gestión preventiva y la adaptación a la escasez que correspondería a territorios especialmente vulnerables a los episodios de sequía. 


\section{Diseño del cuestionario}

El cuestionario diseñado por el equipo del Observatorio Ciudadano de la Sequía tiene como antecedentes algunas experiencias exitosas desarrolladas por el Instituto de Estudios Sociales Avanzados del Consejo Superior de Investigaciones Científicas (IESA-CSIC), como el Ecobarómetro de Andalucía, que de forma discontinua se realizó desde 2001 hasta 2018, y la Encuesta Deliberativa del Agua en 2008.

El cuestionario consta de seis preguntas sobre recursos hídricos y su gestión, centradas en el contexto territorial cercano al encuestado, es decir, su cuenca o demarcación hidrográfica. En primer lugar, se insta al encuestado a realizar un diagnóstico de los principales problemas del agua en su cuenca/demarcación, eligiendo los dos más graves entre un conjunto de ocho problemas. A continuación, se explora el riesgo percibido sobre el cambio climático según si consideran que el fenómeno es un problema actual o aplazan sus efectos a corto o largo plazo (este indicador ha sido utilizado desde hace años en estudios de ámbito internacional y nacional, lo que permite comparar resultado en otros ámbitos espaciales). La tercera pregunta indaga en el conocimiento que tiene la población sobre la distribución del uso del agua entre sectores productivos, siendo la información o desinformación sobre este tema el factor que más claves ha aportado en los estudios previos llevados a cabo por el equipo del Observatorio para explicar las preferencias de los ciudadanos sobre los modelos de gestión del agua. Precisamente, conocer tales preferencias es el objetivo de la cuarta pregunta, que ofrece una batería de nueve medidas de gestión entre las que los encuestados pueden elegir las dos que consideran más adecuadas para su cuenca/demarcación. La quinta pregunta es central para incorporar la opinión de la ciudadanía al diseño de las políticas de adaptación a los riesgos de sequía dado que se solicita a los/as encuestados/as que valoren la eficacia de quince medidas que podrían implementarse para reducir la vulnerabilidad de su territorio ante estos episodios futuros. La efectividad de las medidas depende en gran parte del grado de confianza que los ciudadanos depositen en las instituciones encargadas de su desarrollo, cuestión que es abordada en la sexta pregunta a la que se incorpora otros actores sociales relevantes en la política hidrológica como son organizaciones agrarias, comunidad científica, organizaciones ecologistas y medios de comunicación
Por último, se incluye un bloque de preguntas sociodemográficas (sexo, edad, nive educativo, zona de residencia) destinadas a clasificar las opiniones recogidas en las preguntas anteriores. El cuestionario se cierra con dos preguntas cuya finalidad es valorar el interés suscitado por la información contenida en el portal y el geovisor del Observatorio Ciudadano de la Sequía.

\section{Ficha técnica}

\section{Ámbito de referencia visitantes página web del cuestionario}

Universo personas con 18 años o más

Tamaño de la muestra 615 entrevistas

Tipo de entrevista online

no probabilístico, en el que la difusión del enlace al
cuestionario ha utilizado varias vías: listas de
distribución de correos electrónicos, Twitter,
anuncios en Facebook y Linkedin, así como la
difusión realizada por las propias personas
encuestadas con objeto de llegar a un público lo
más heterogéneo posible




\section{Referencias}

Lafuente, R., Ganuza, E., \& Paneque, P. (2020). Social Resistance to the Hydrological Transition in Southern Spain: Public Support for the Building of New Reservoirs. Resources. https://doi.org/10.3390/resources 9030022

Lafuente, R., Paneque, P., \& Cañadas, J.L. (2021). The Gender Gap in Water Management Preferences: Analyzing the Influence of Environmental Concern and Political Knowledge. Society \& Natural Resources. https://doi.org/10.1080/08941920.2021.1971808

Lafuente, R., Paneque, P., \& Vargas, J. (2018). The Role Played by Environmental Concern and Institutional Trust in Changing Public Preferences for Water Management. Environmental Policy and Governance, 28, 441-452. http://dx.doi.org/10.1002/eet.1808

Paneque, P. (2015). Drought Management Strategies in Spain". Water, 7(12), 66896701. https://doi.org/10.3390/w7126655

Paneque, P., \& Vargas, J. (2015). Drought, social agents and the construction of discourse in Andalusia. Environmental Hazards: Human and Policy Dimensions, 14(3), 224-235. https://doi.org/10.1080/17477891.2015.1058739

Paneque, P., Lafuente, R., \& Vargas, J. (2018). Public Attitudes toward Water Management Measures and Drought: a study in Southern Spain. Water, 10(4) https://doi.org/10.3390/w10040369

Vargas, J., \& Paneque, P. (2019). Challenges for the integration between water resource management and drought risk management in Spain. Sustainability, 11(308). https://doi.org/10.3390/su11020308

Vargas, J., \& Paneque, P. (2017). Methodology for the analysis of causes of drought vulnerability on the River Basin scale. Natural Hazards, 89(2), 609-621. https://doi.org/10.1007/s11069-017-2982-4

Vargas, J., Paneque, P., \& Breda, P. (2021). Drought-related media analysis from Andalusia and São Paulo. Environmental Hazards. https://doi.org/10.1080/17477891.2021.1932712 


\section{RESULTADOS}

\section{Caracterización de la muestra}
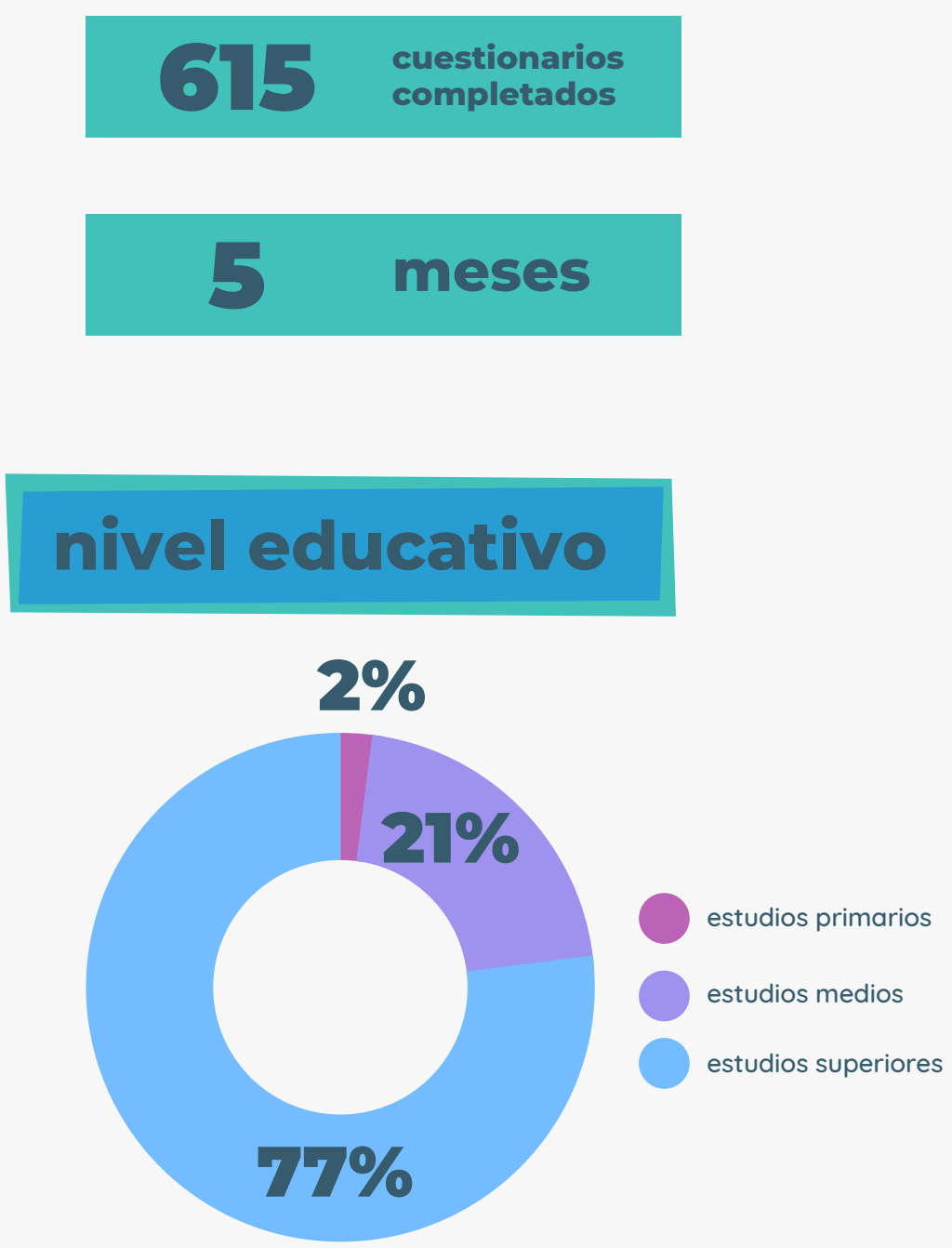

\section{edad}

$\begin{array}{rr}<25 & 24 \% \\ 25-40 & 19 \% \\ 40-60 & 48 \% \\ >60 & 9 \%\end{array}$

\section{género}

\section{$39.6 \%$ \\ $60.4 \%$}

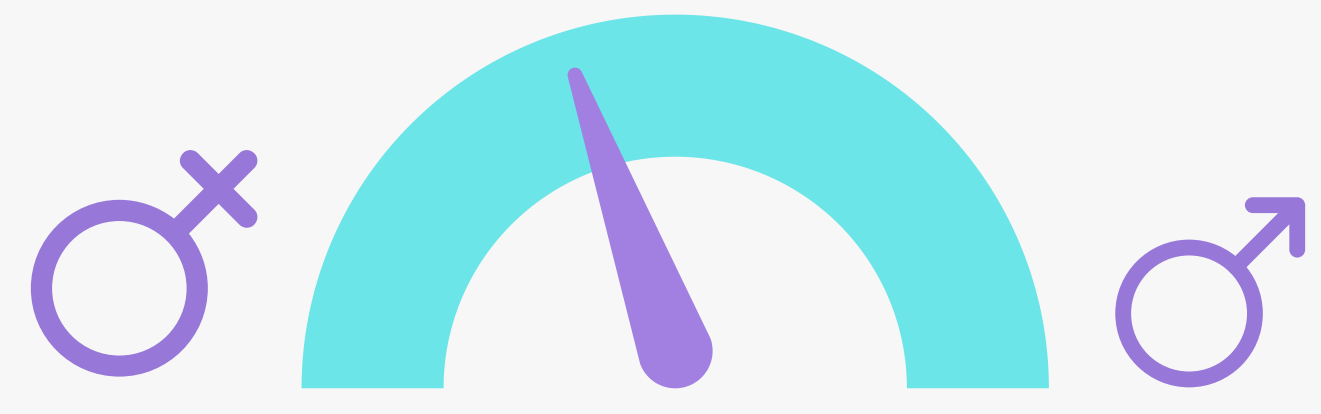




\section{PREGUNTA 1}

Del siguiente listado de problemas relacionados con el agua, ¿podría decirme los dos más importantes que, en su opinión, tiene hoy su cuenca/demarcación?

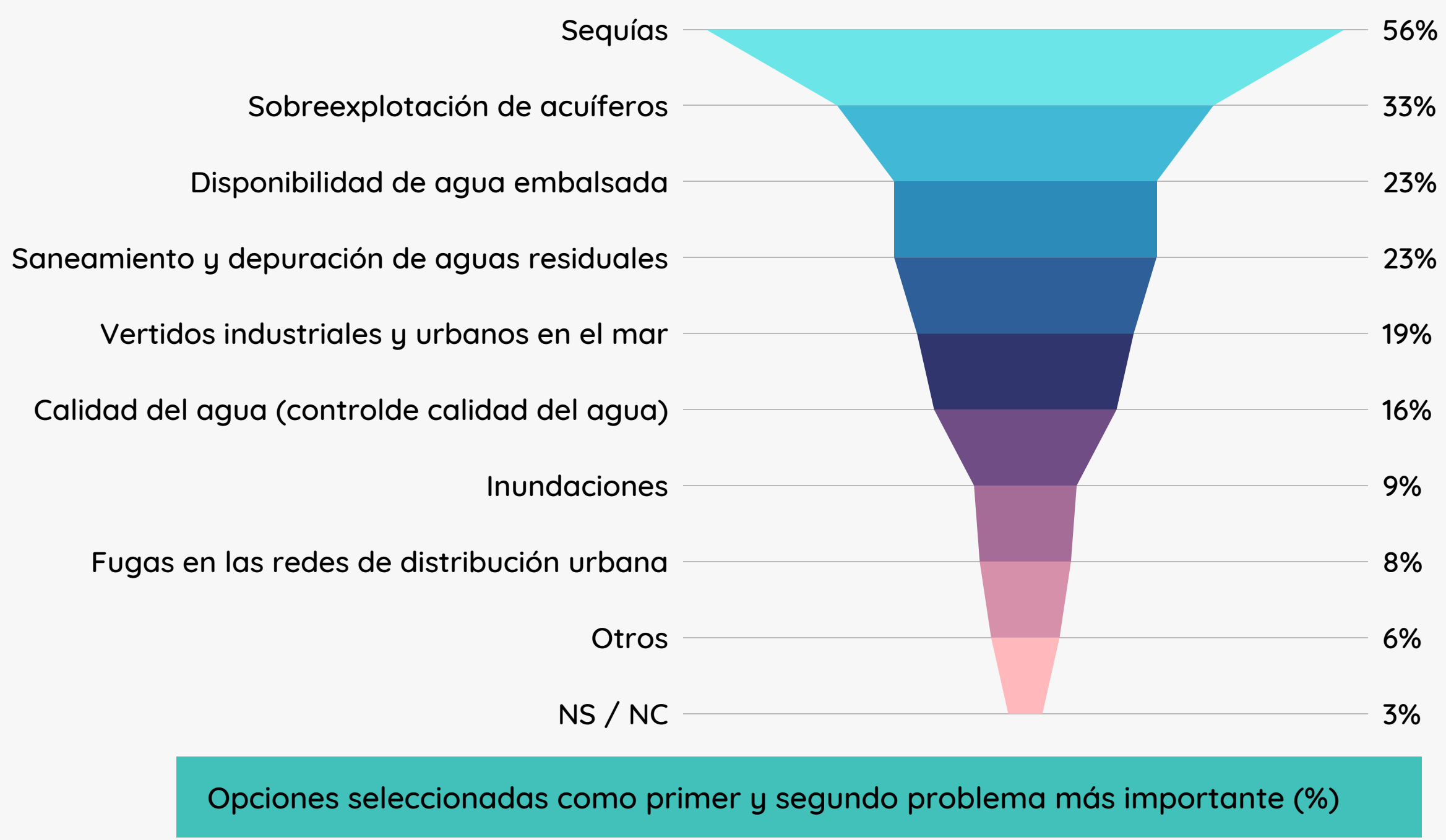




\section{PREGUNTA 1 resultados por edad}

Disponibilidad de agua embalsada

Inundaciones

Sequías

Calidad del agua (controlde calidad del agua)

Saneamiento y depuración de aguas residuales

Vertidos industriales y urbanos en el mar

Fugas en las redes de distribución urbana

Sobreexplotación de acuíferos

$<25$ años

25-40 años

40-60 años

$>60$ años
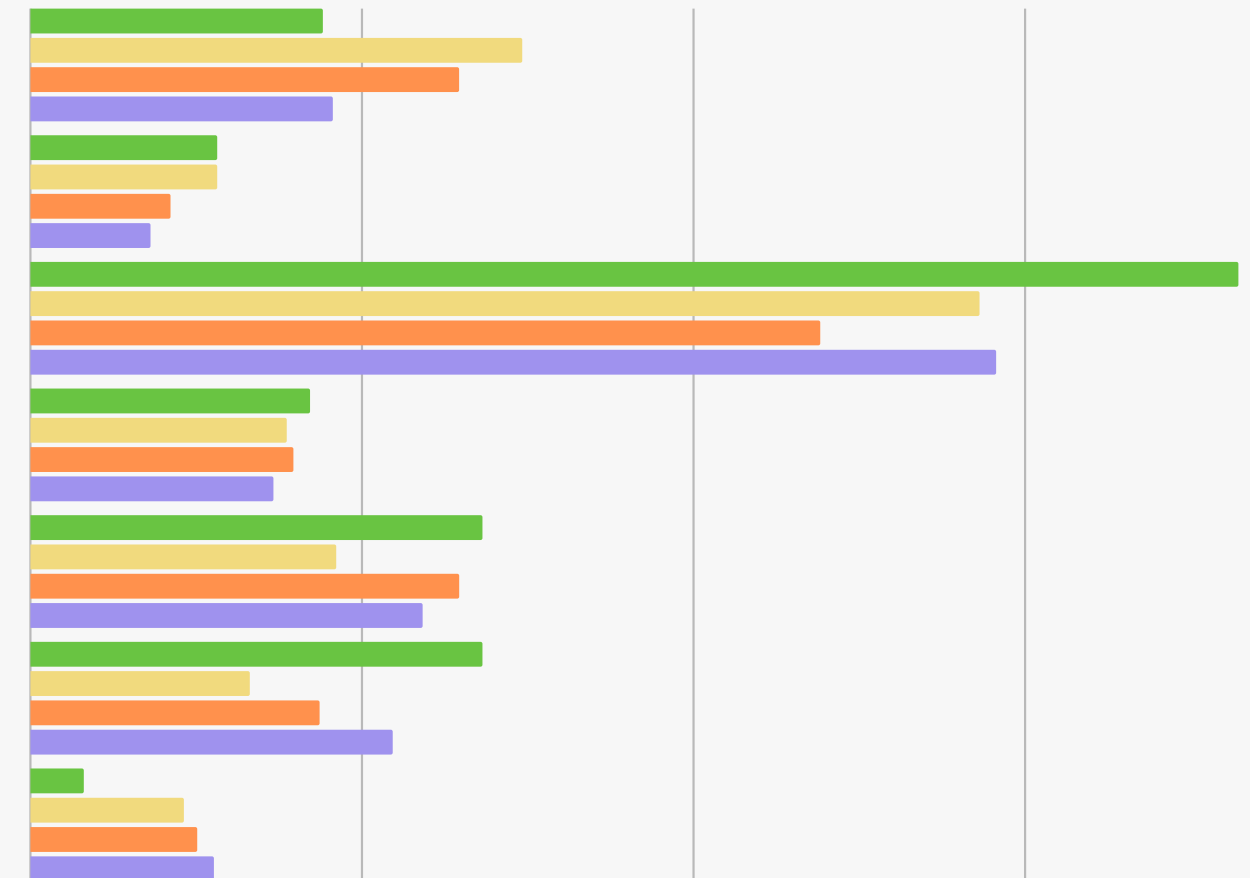

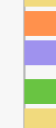

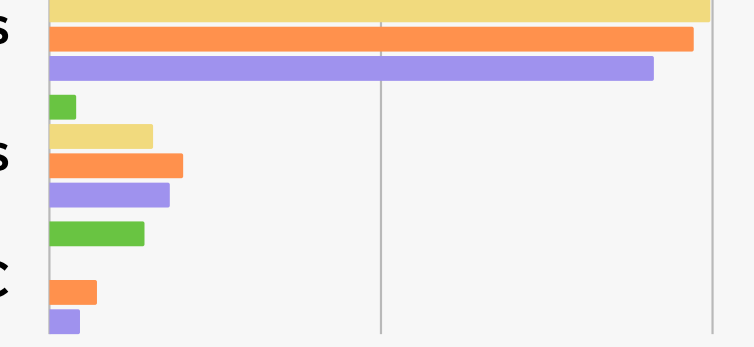

$0 \%$

$10 \%$

$20 \%$

$30 \%$

$40 \%$ 


\section{PREGUNTA 1 resultados por género}

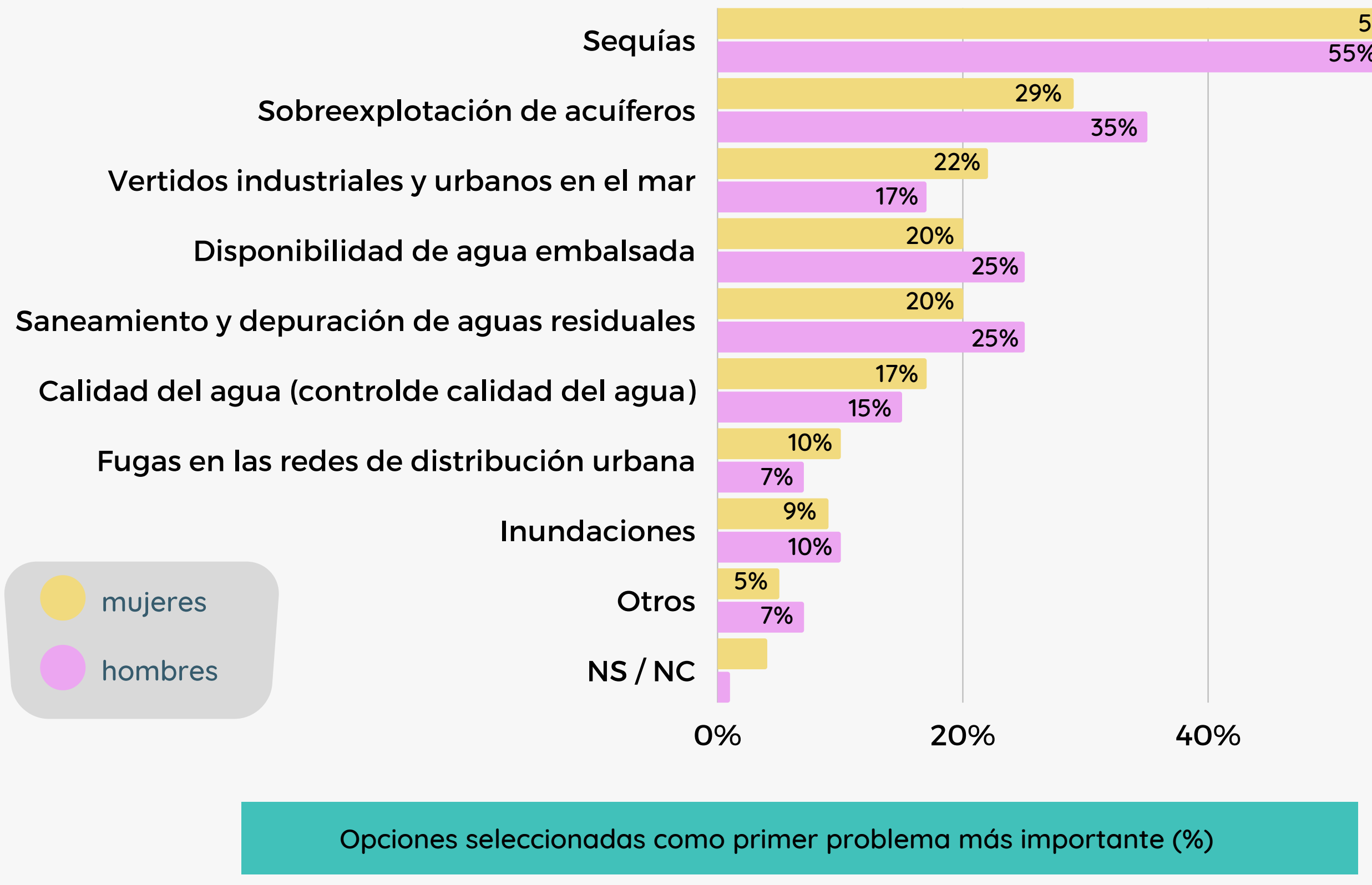




\section{PREGUNTA 2}

¿Considera usted que en los últimos años estamos asistiendo a un cambio en el clima del planeta producido por la emisión de gases de efecto invernadero?

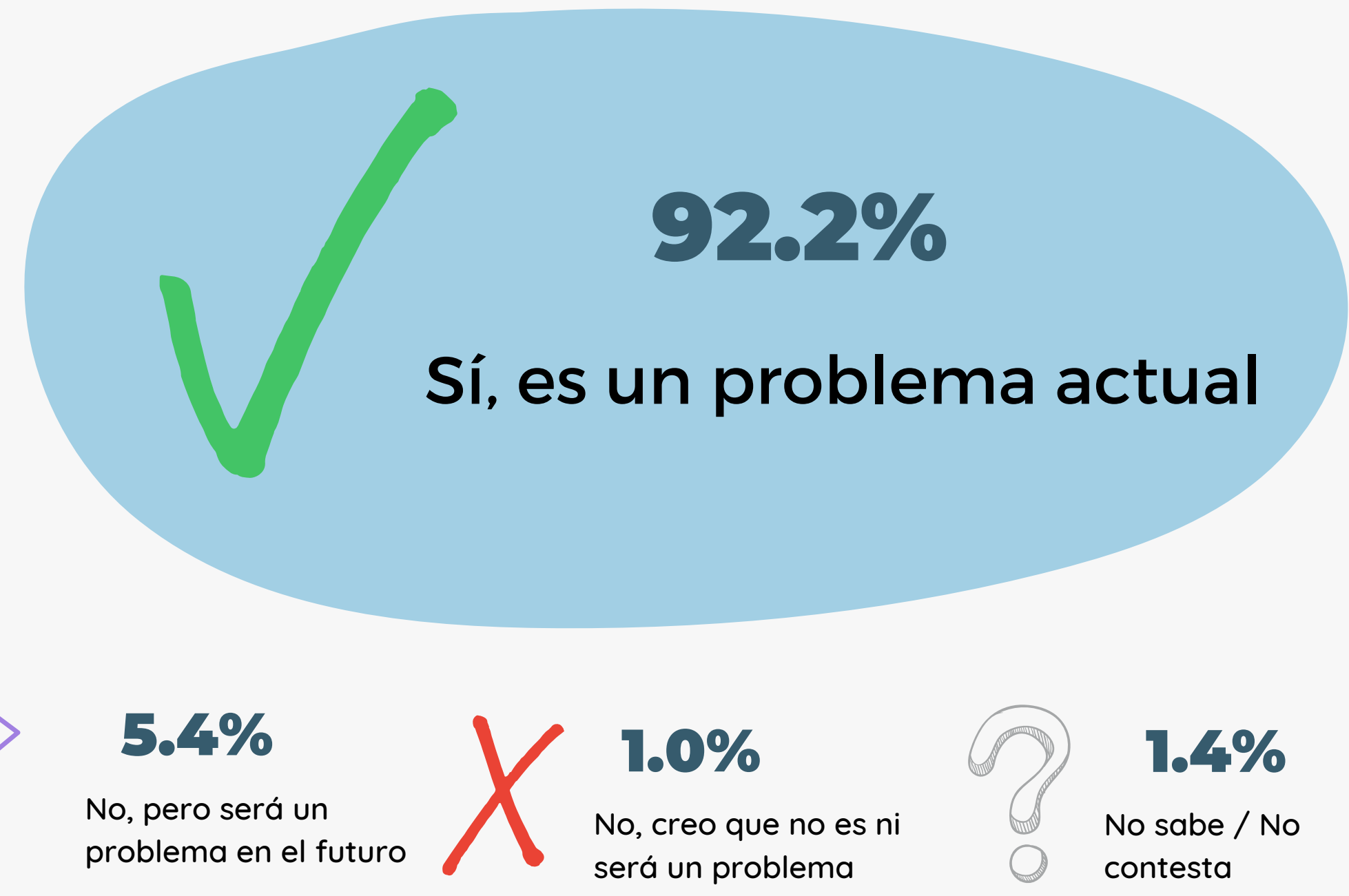




\section{PREGUNTA 2}

\section{¿Considera usted que} en los últimos años estamos asistiendo a un cambio en el clima del planeta producido por la emisión de gases de efecto invernadero?

no sabe / no contesta

No, creo que no es ni será un problema

No, pero será un

problema en el futuro

Sí, es un problema actual

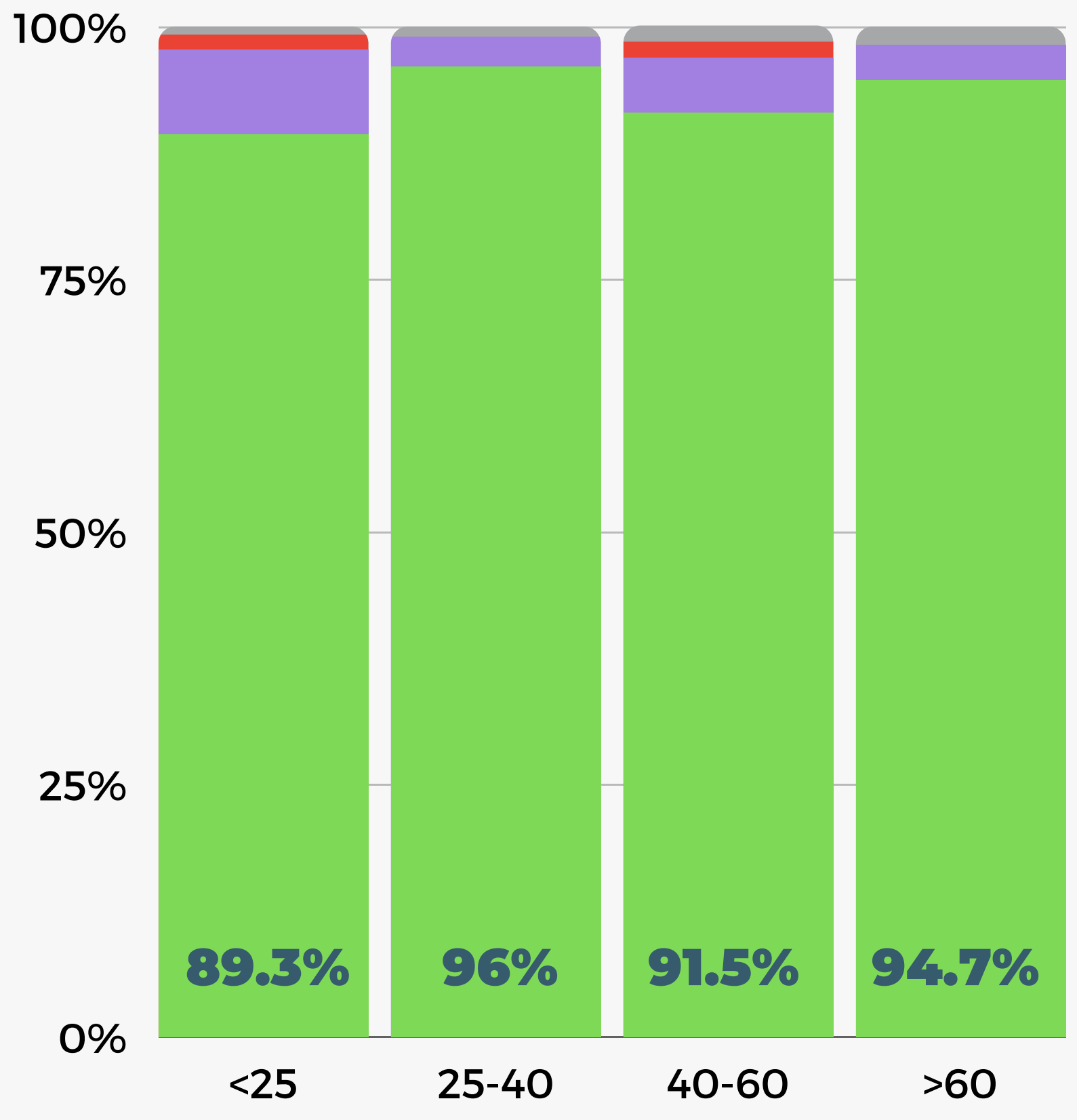




\section{PREGUNTA 3}

¿Dónde considera usted que se produce el mayor consumo de agua?

\section{$49.3 \%$ agricultura}

$9.8 \%$ hogares
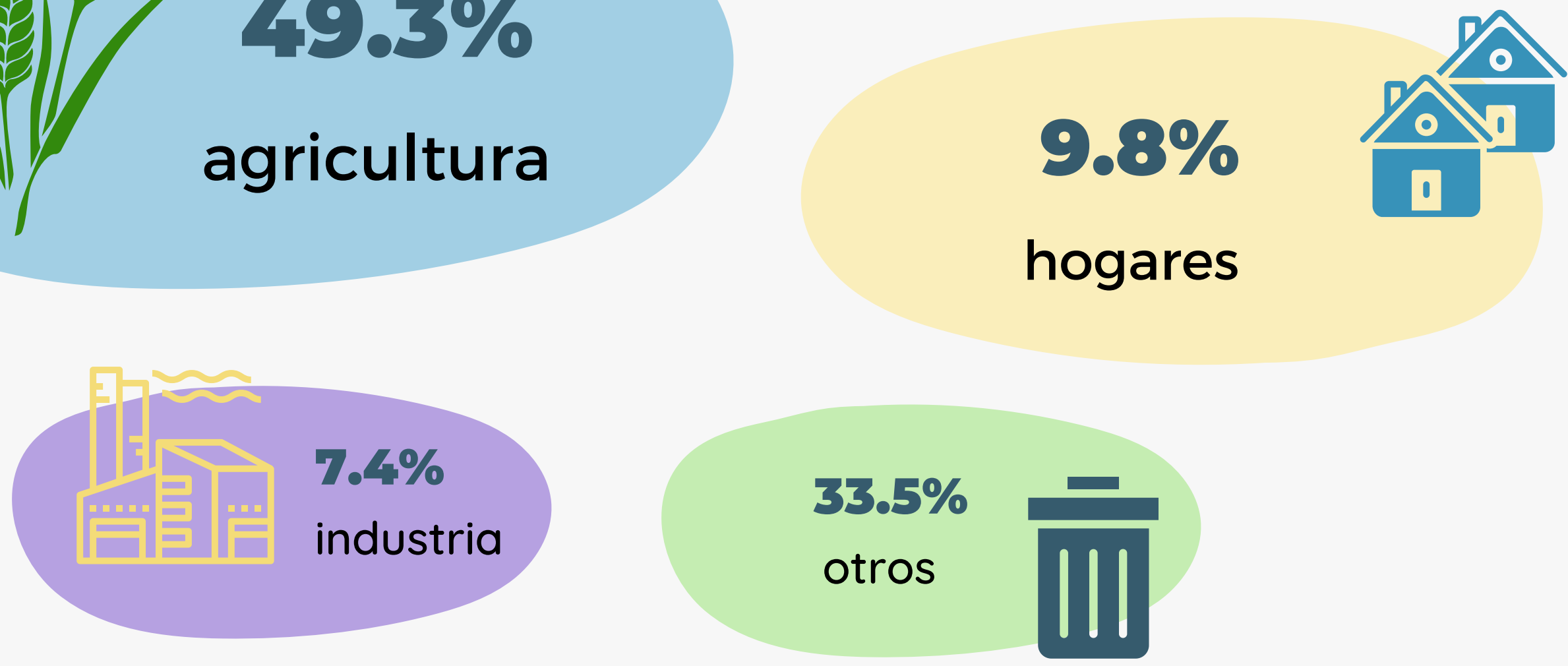


\section{PREGUNTA 3}

\section{resultados por género}
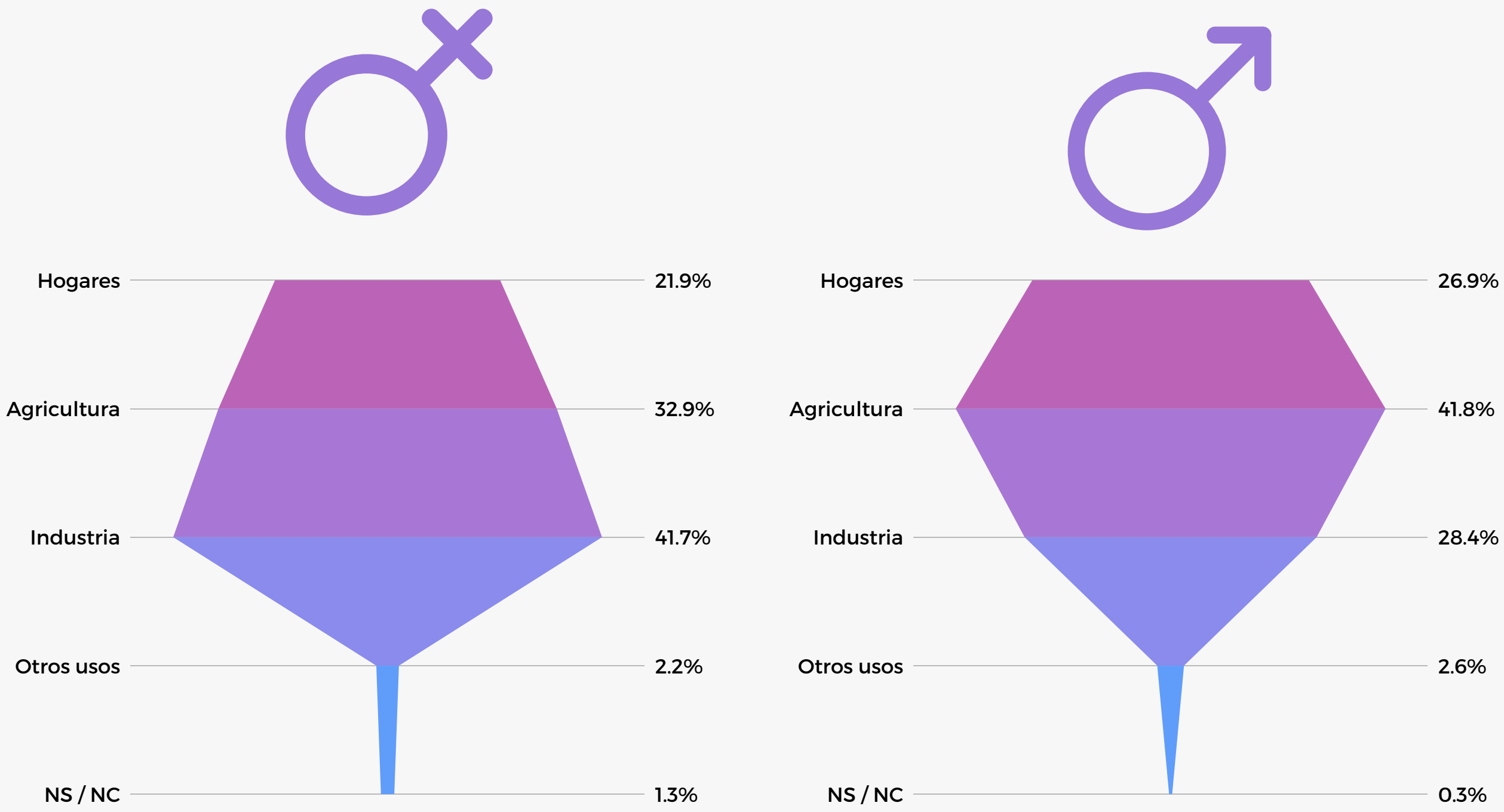


\section{PREGUNTA 3}

\section{resultados por nivel educativo}
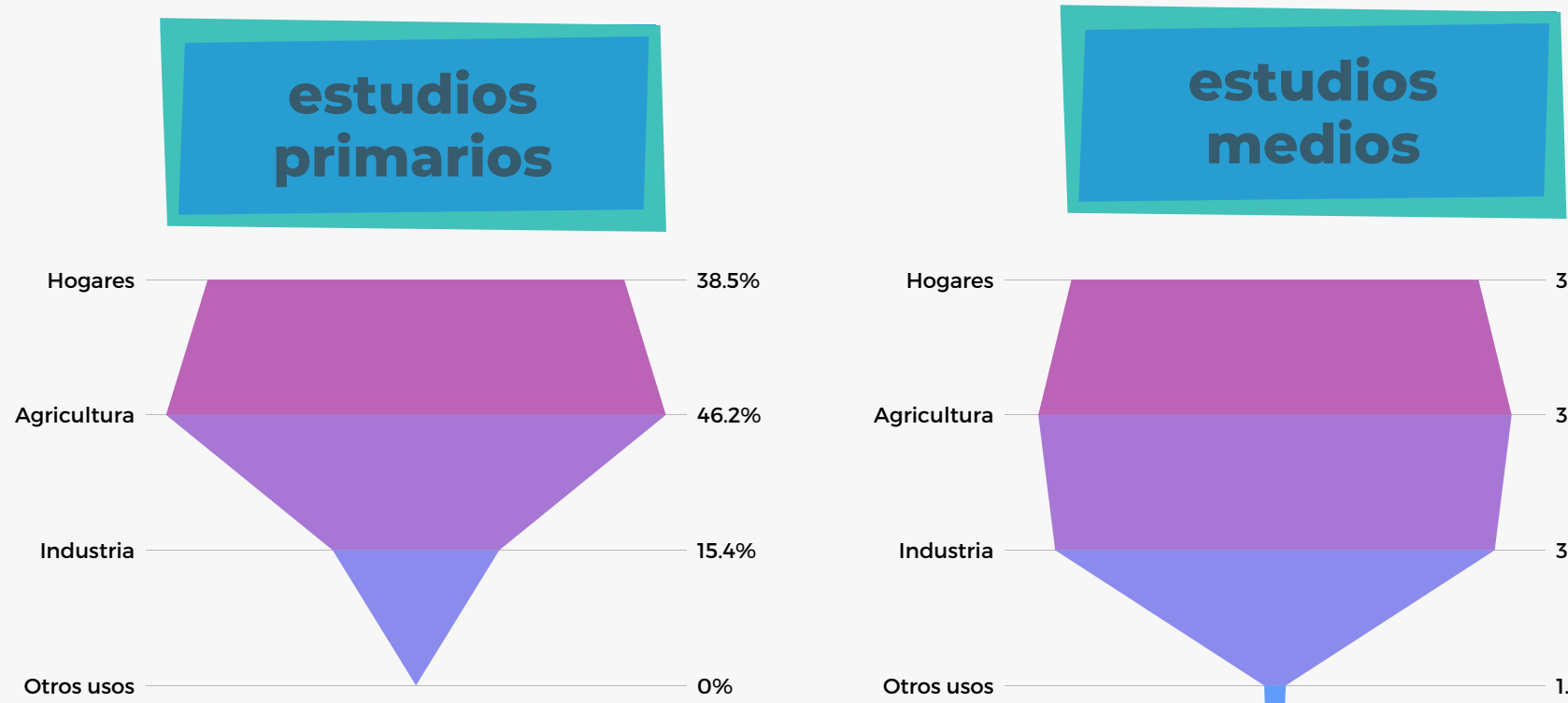

NS / NC

$0 \%$
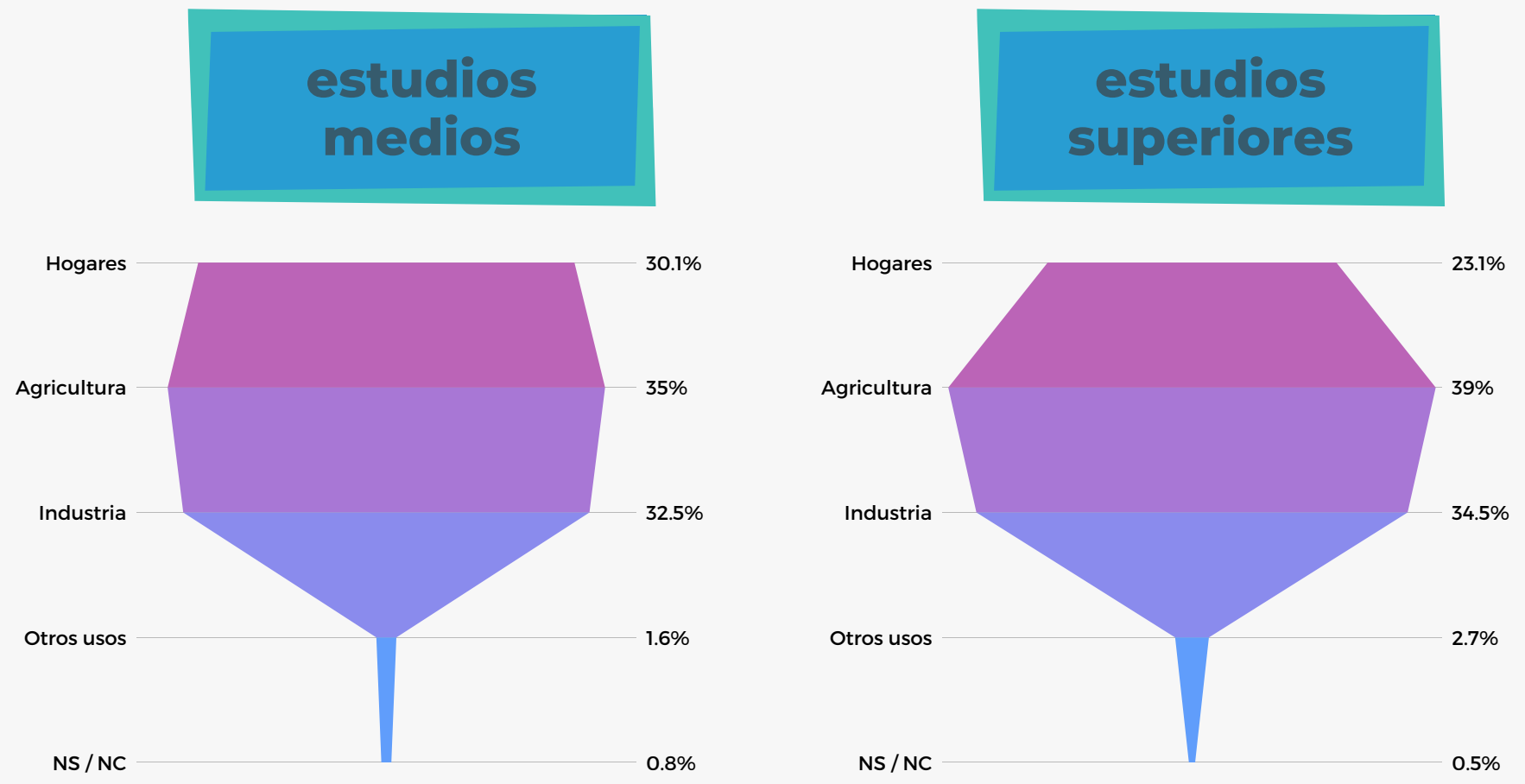


\section{PREGUNTA 3 resultados por edad}

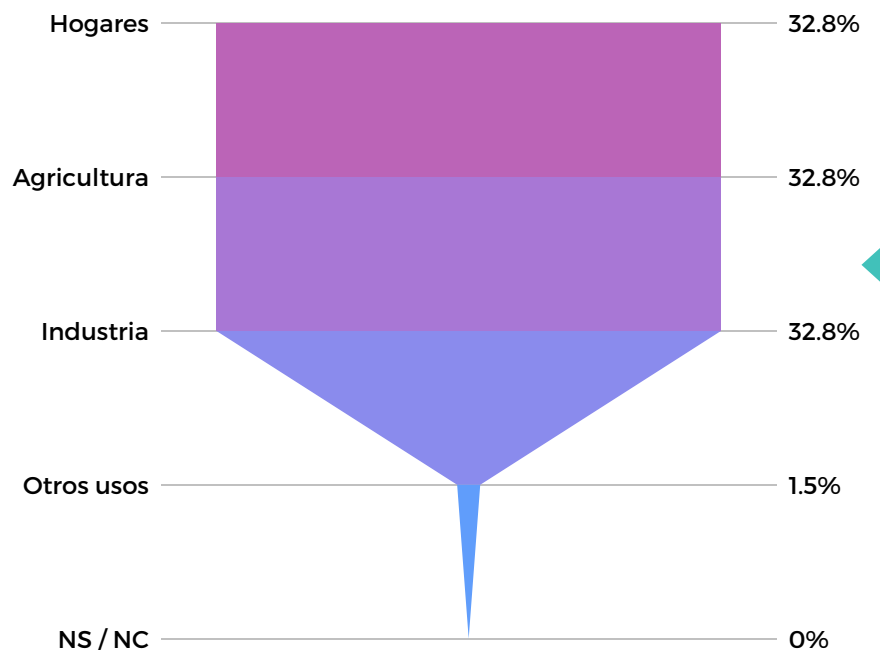

NS / NC $0 \%$

$-23.7 \%$

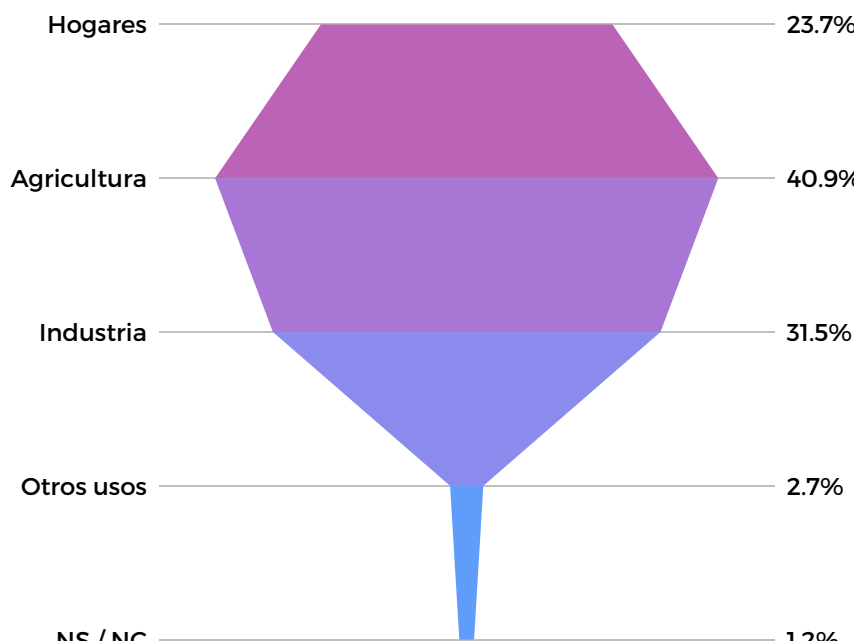

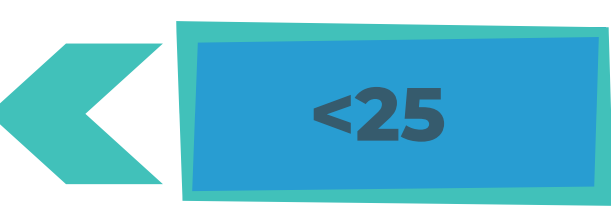

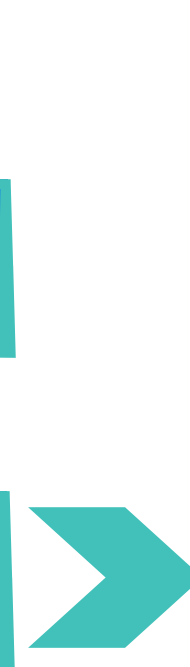

Hogares
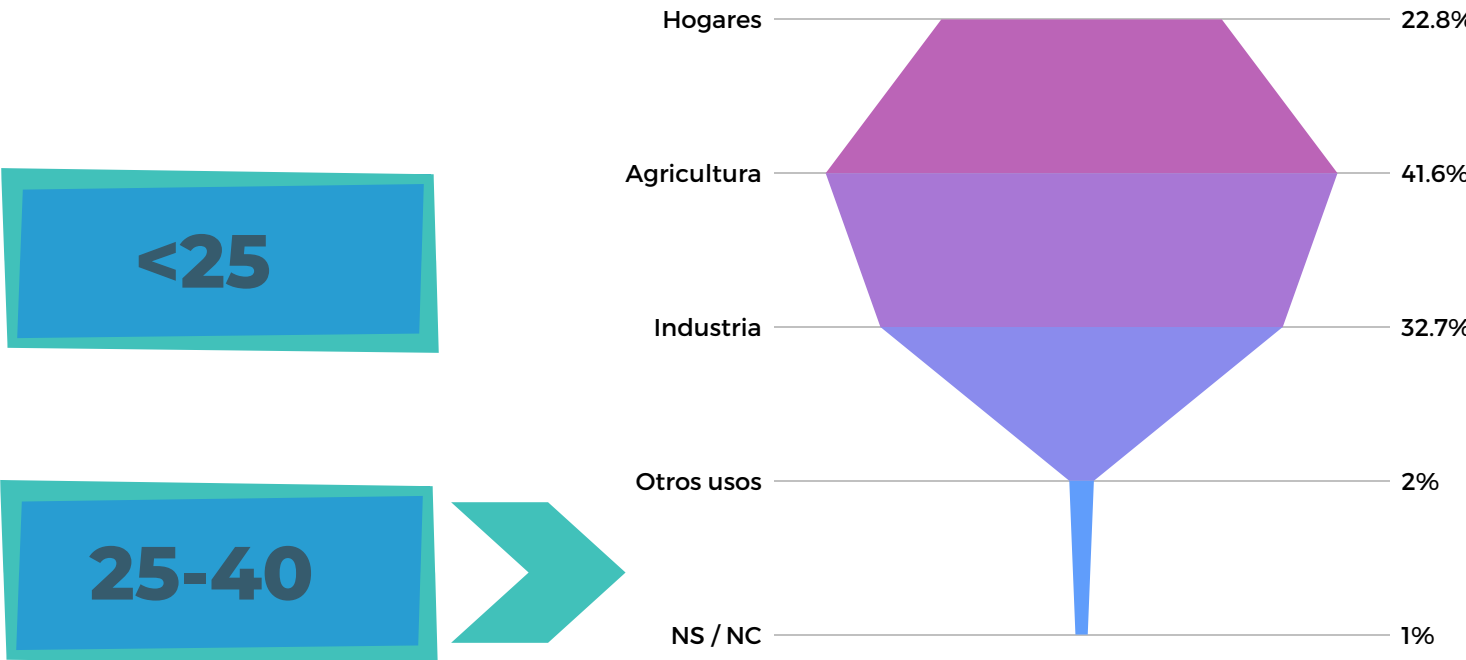

Otros uso
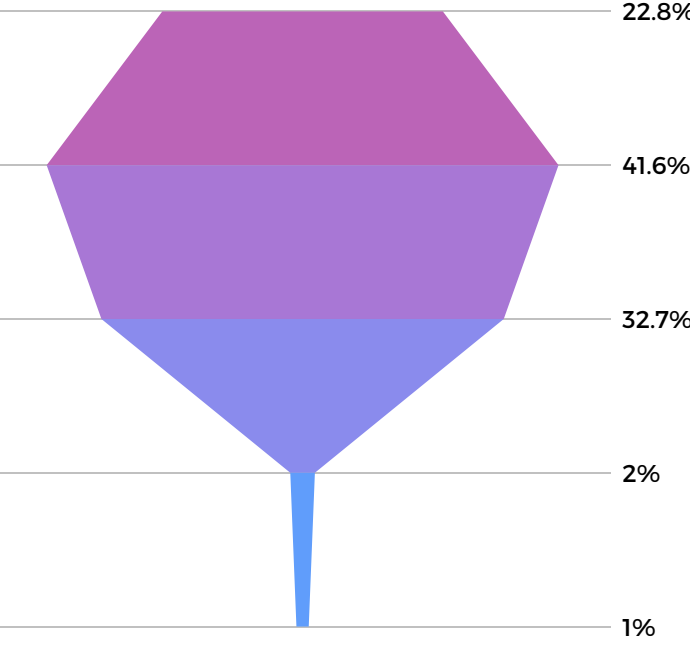

NS / NC

$1 \%$

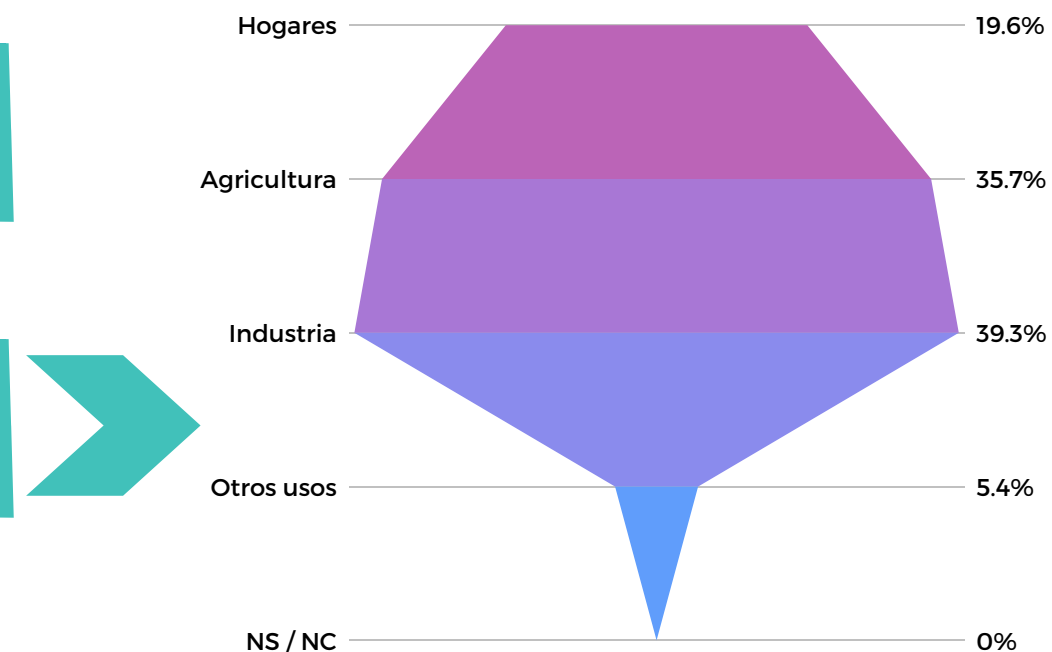

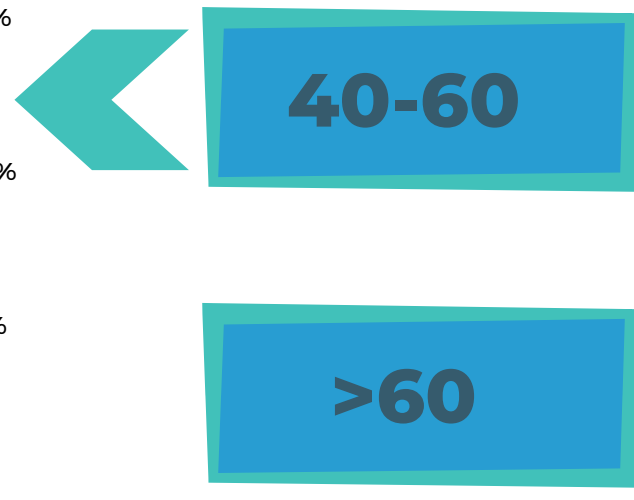

$1.2 \%$
NS / NC

$0 \%$ 


\section{PREGUNTA 4}

Del siguiente conjunto de medidas relacionadas con la gestión del agua, ¿cuál considera usted que sería la más adecuada para su cuenca/demarcación?

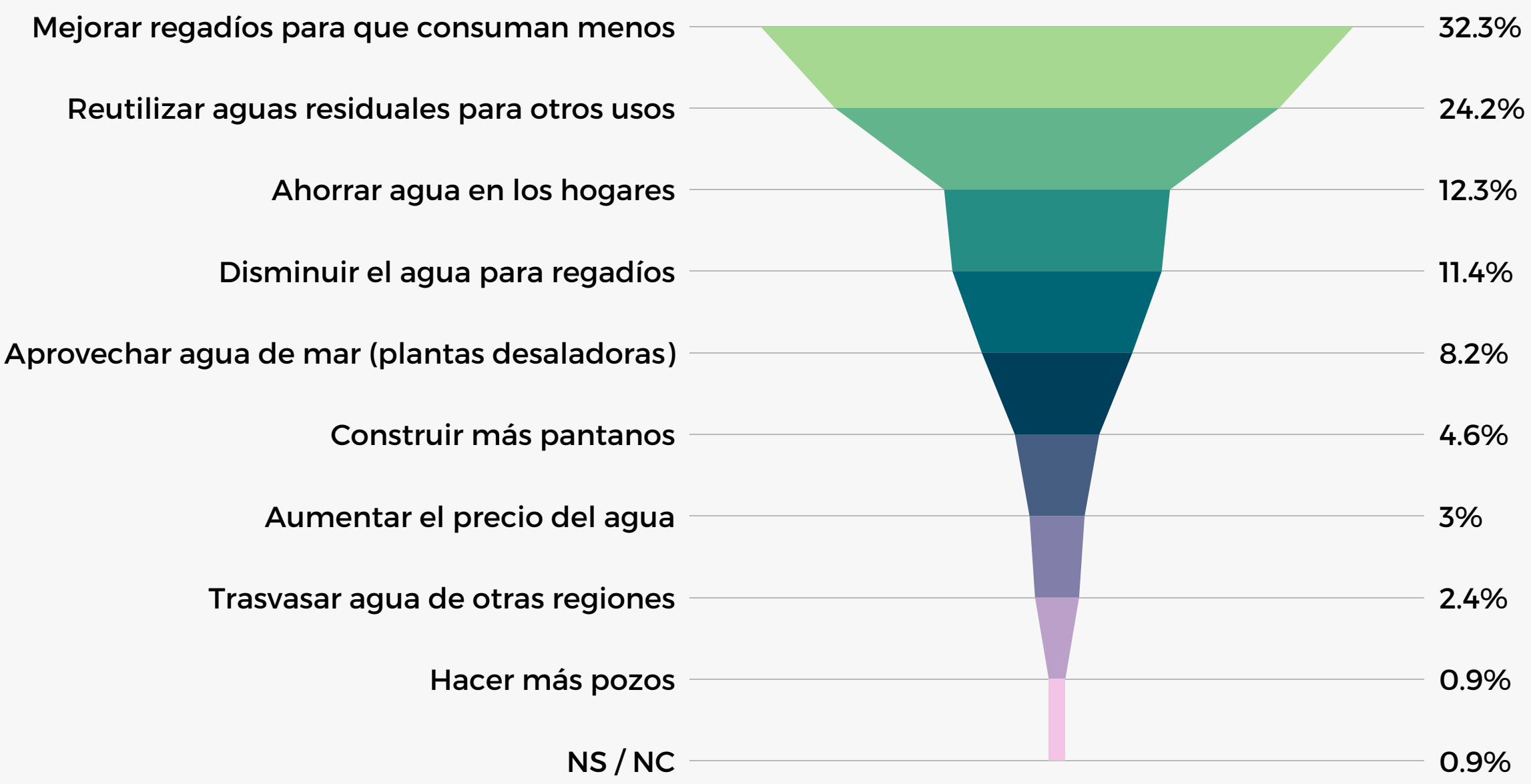

Opciones seleccionadas como primera o segunda medida más adecuada (\%) 


\section{PREGUNTA 4 resultados por género}

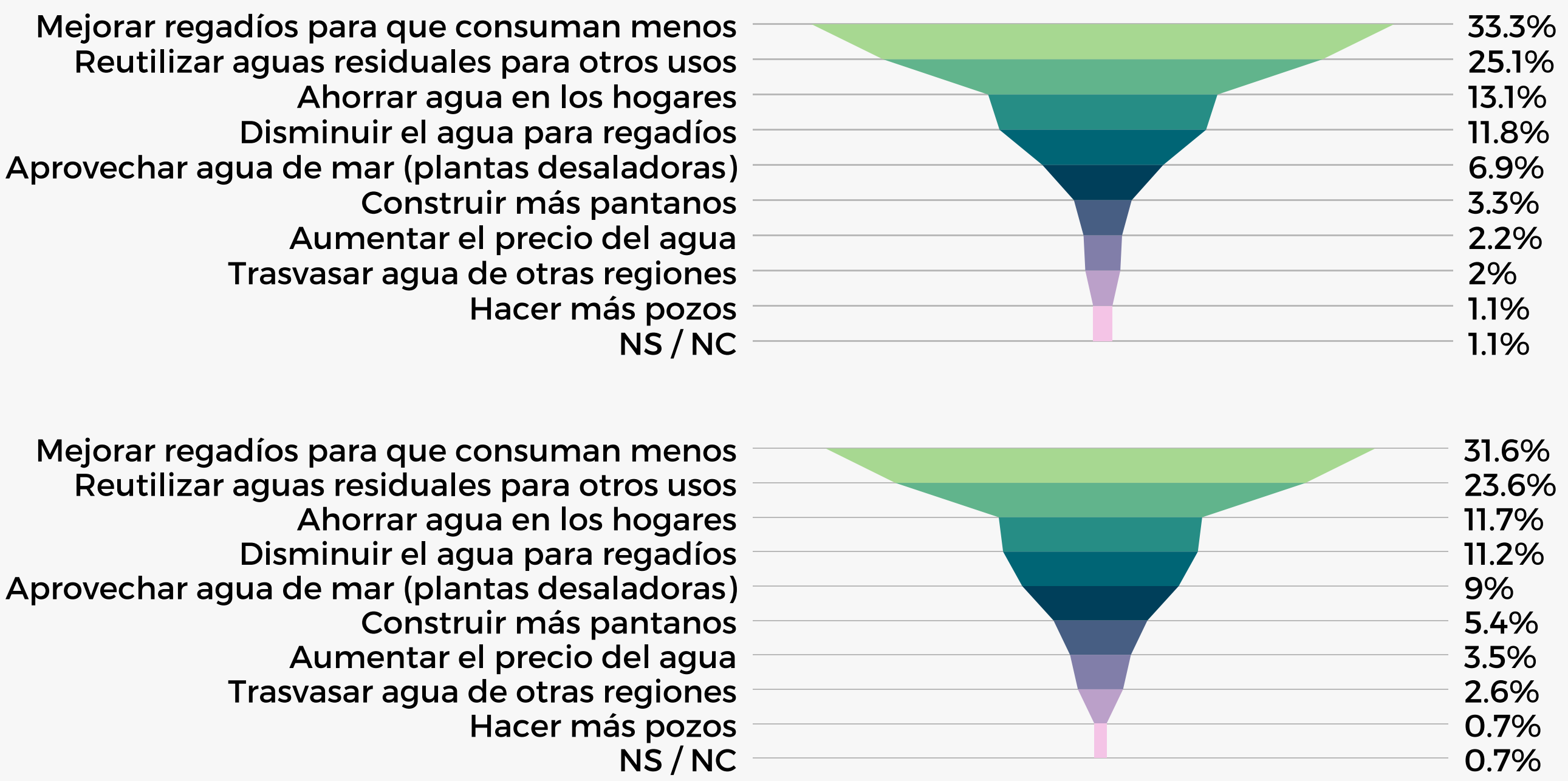




\section{PREGUNTA 4}

Las tres medidas principales elegidas por los participantes son:

\section{$32.3 \%$}

mejorar los regadíos para que consuman menos

\section{$12.3 \%$}

ahorrar agua en los hogares
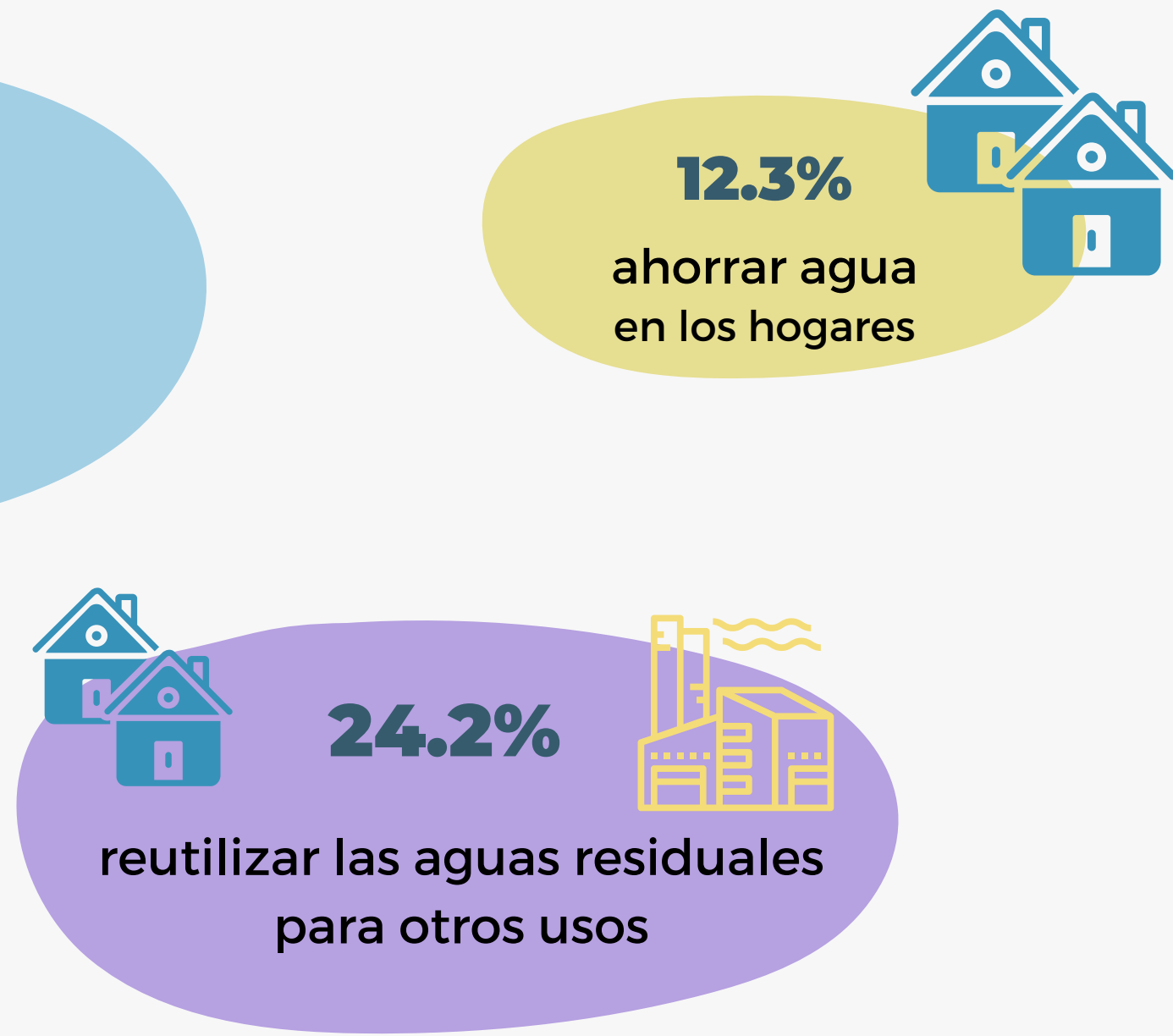

Opciones seleccionadas como primera o segunda medida más adecuada (\%) 


\section{PREGUNTA 4}

\section{resultados por nivel educativo para las tres medidas principales}
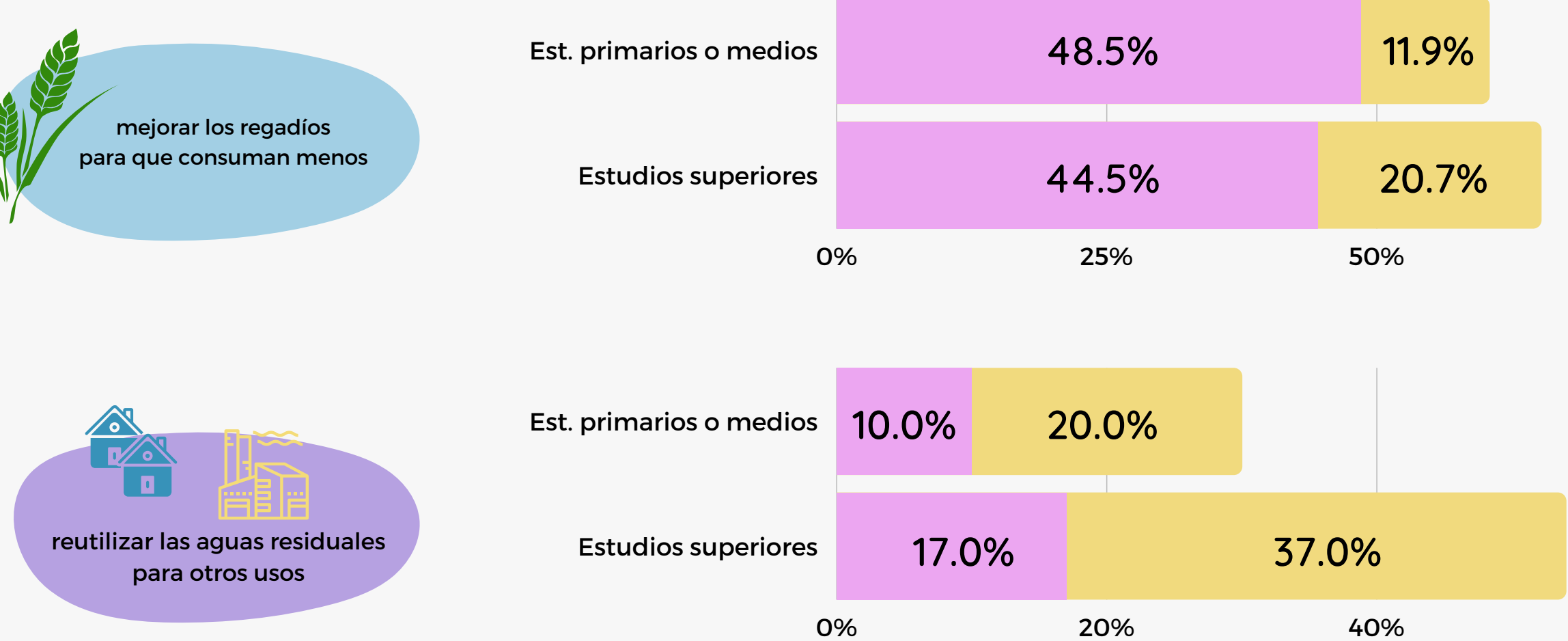

$60 \%$

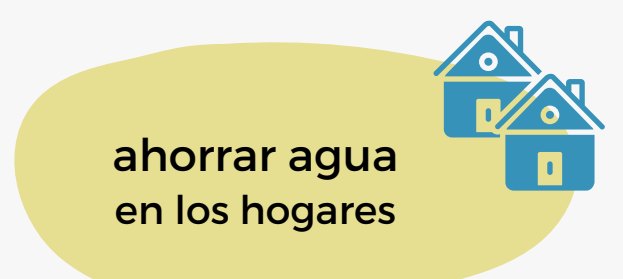

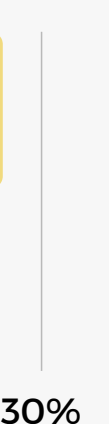




\section{PREGUNTA $4 \begin{aligned} & \text { resultados por edad } \\ & \text { para las tres medidas principales }\end{aligned}$}

\begin{tabular}{r|cc|}
$<25$ & $46.7 \%$ & $12.9 \%$ \\
\hline $25-40$ & $46.2 \%$ & $25.7 \%$ \\
\hline $40-60$ & $39.3 \%$ & $16.3 \%$ \\
\hline 60 & $39.7 \%$ & $18.1 \%$ \\
\hline $0 \%$ & $25 \%$ & $50 \%$
\end{tabular}

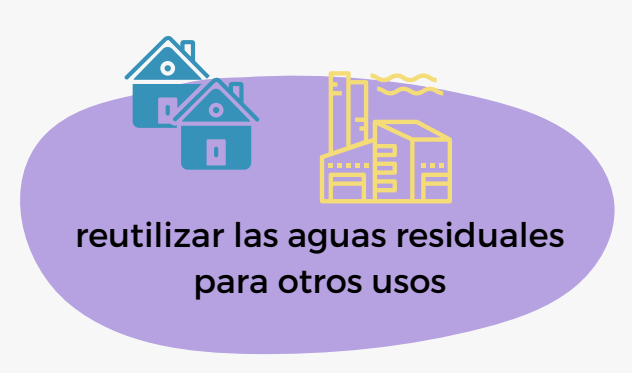

\begin{tabular}{r|rr|r|}
\hline$<25$ & $31.8 \%$ & $20.3 \%$ \\
\hline $25-40$ & $24.0 \%$ & & $37.7 \%$ \\
\hline $40-60$ & $12.9 \%$ & $33.5 \%$ & \\
\hline$>60$ & $12.6 \%$ & $28.9 \%$ & \\
\hline $0 \%$ & $25 \%$ & $50 \%$
\end{tabular}

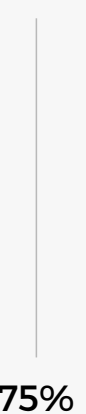

ahorrar agua

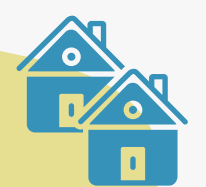
en los hogares

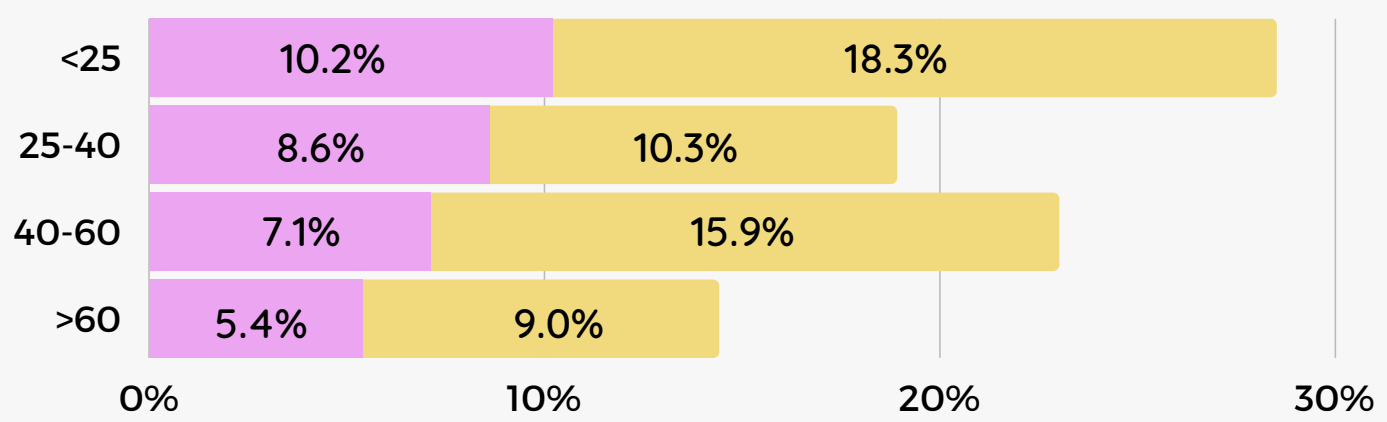




\section{PREGUNTA 5}

\section{Según su opinión, y centrándonos en las sequías, ¿cuál es el grado de importancia de las siguientes medidas destinadas a evitar los efectos de las futuras sequías en su cuenca/demarcación?}

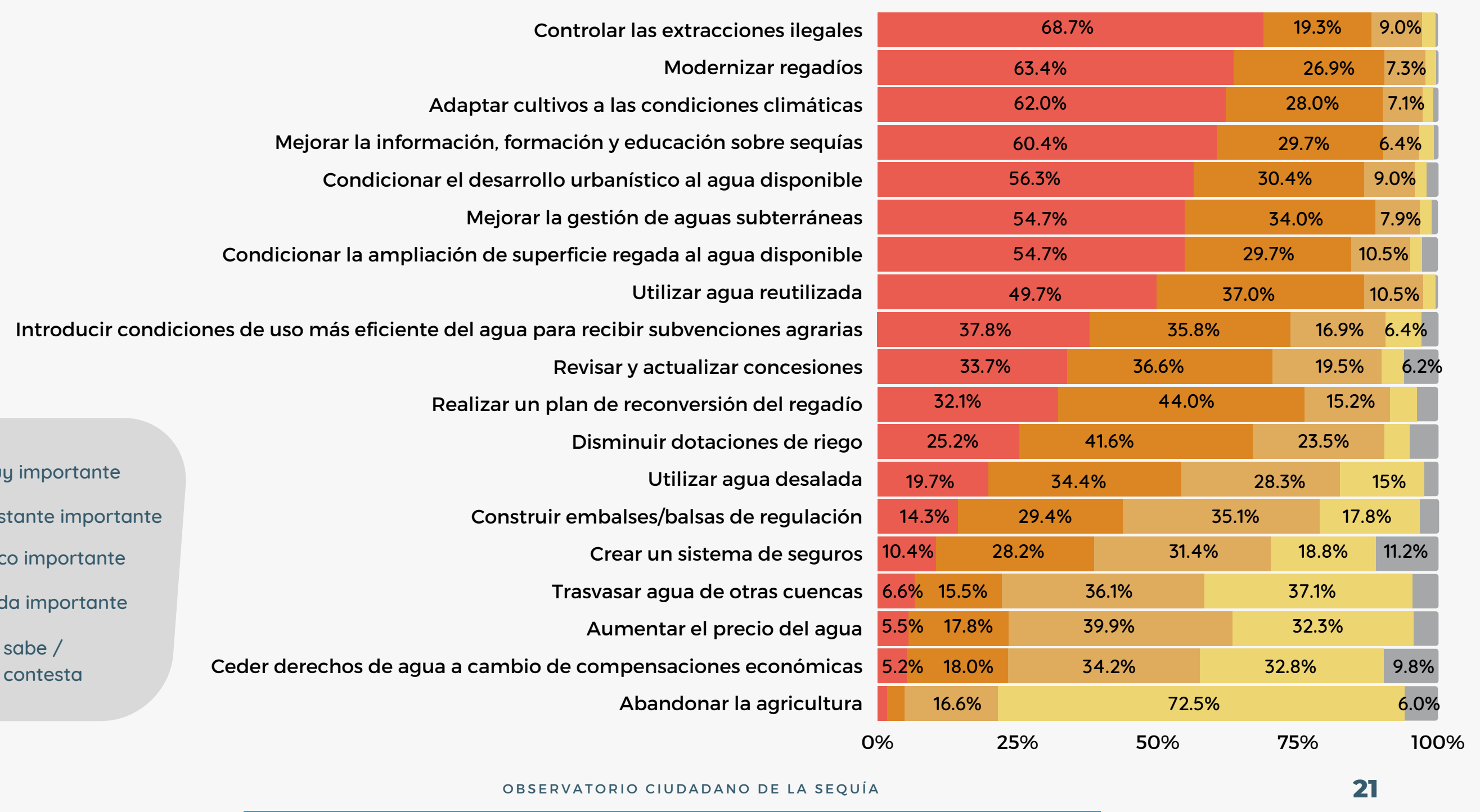




\section{PREGUNTA 6}

¿Podría decirme qué grado de confianza le merece las siguientes instituciones?

mucha confianza

bastante confianza

alguna confianza poca confianza

ninguna confianza

no sabe / no contesta

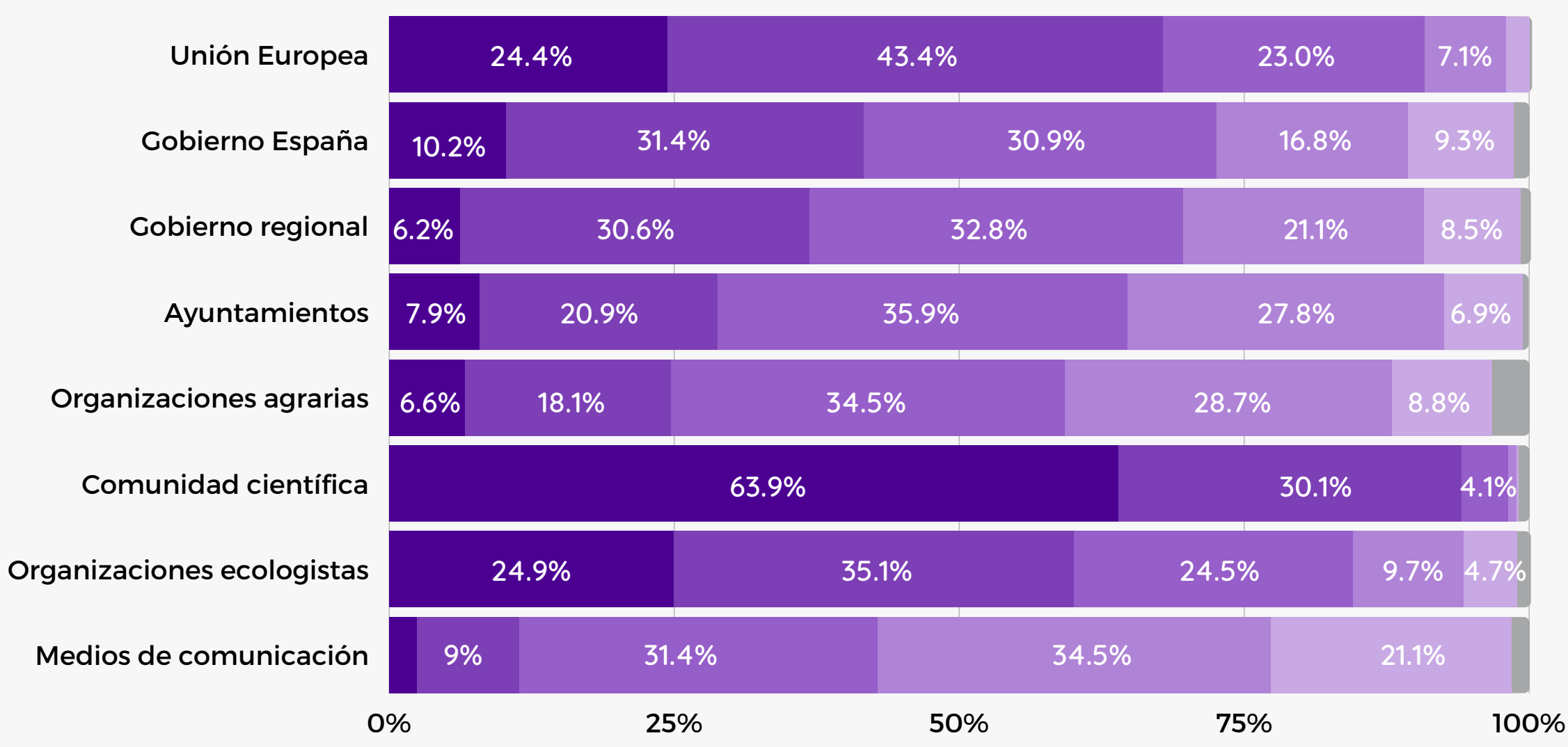




\section{PREGUNTA 6}

\section{Desglose por institución}

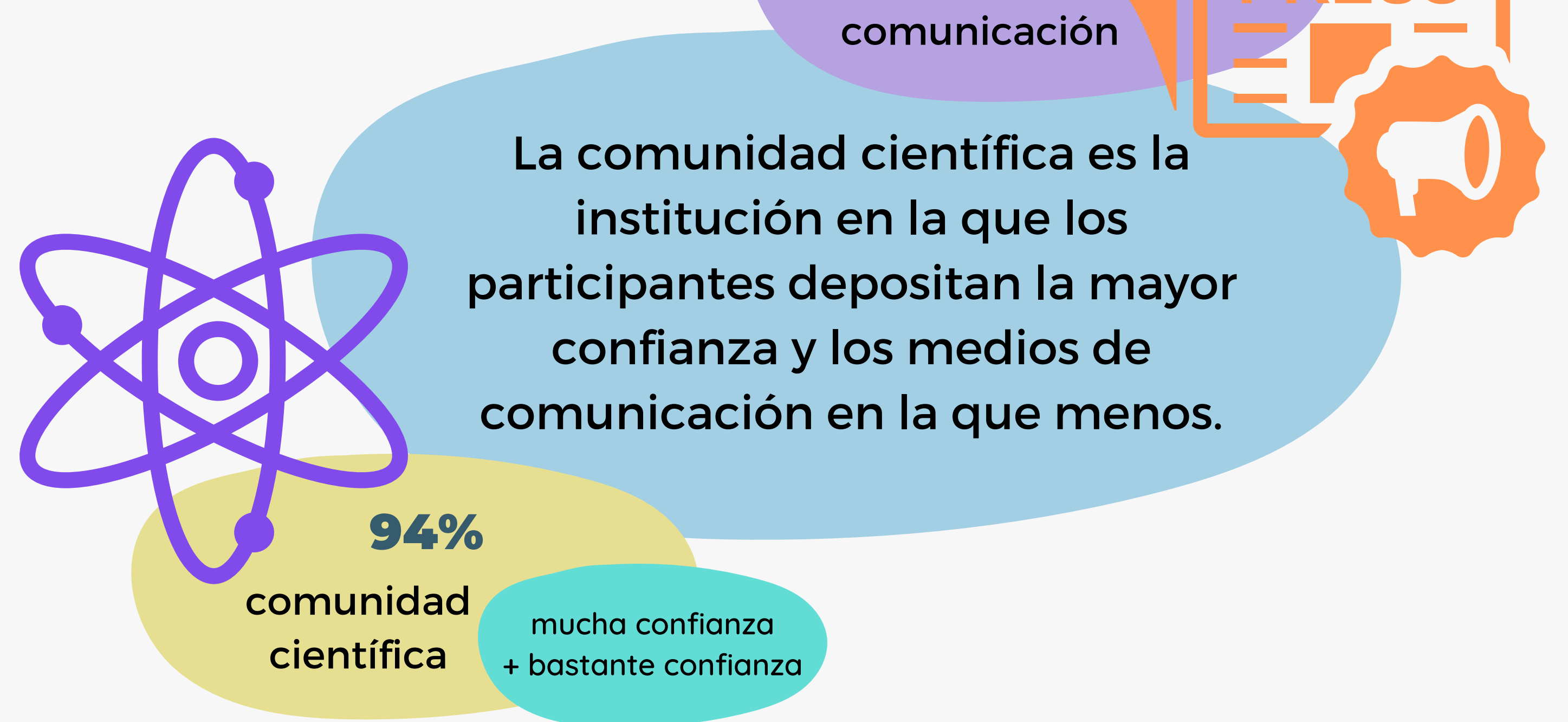

poca confianza

+ ninguna confianza $5.6 \%$

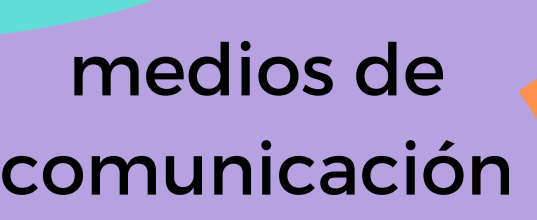




\section{ANEXO}

\section{Cuestionario realizado}

Enlace disponbile en:

https://observasequia.es/cuestionario/

P.1.1. Del siguiente listado de problemas relacionados con el agua, ¿podría decirme los dos más importantes que, en su opinión, tiene hoy su Cuenca/Demarcación? SOLO UNA RESPUESTA POR COLUMNA.

$$
\text { Primer problema }
$$

Segundo problema

\section{Disponibilidad de agua}

embalsada

Inundaciones

Sequías

Calidad del agua (control de la calidad del aguá

Saneamiento y depuración de

\section{las aguas residuales}

Vertidos industriales y urbanos en el mar (Calidad de las aguas

$$
\text { litorales) }
$$

Fugas en las redes de

distribución urbana

Sobreexplotación de acuíferos

Otros

NS

NC



P.2. ¿Considera Ud. que en los últimos años estamos asistiendo a un cambio en el clima del planeta producido por la emisión de gases de efecto invernadero? *

- Si, es un problema actual

No, pero será un problema en el futuro

- No, creo que no es ni será un problema

○ NS

O NC

P.3. El siguiente gráfico representa cómo se reparte en el sur peninsular el consumo de agua entre los hogares, las industrias, la agricultura y otros usos (instituciones públicas como colegios, hospitales, etc., fugas de agua). ¿A cuál de estos cuatro grupos piensa Ud. que corresponde el número 1? ¿y el número 2? ¿y el número 3? ¿y el número 4?

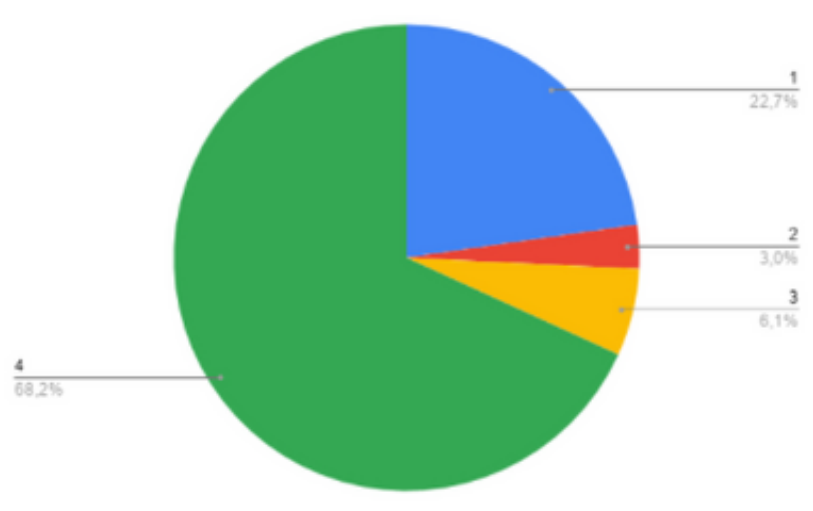

\begin{tabular}{lcccc} 
& Número 1 & Número 2 & Número 3 & Número 4 \\
Hogares & $\circ$ & $\circ$ & $\circ$ & $\circ$ \\
Agricultura & $\circ$ & $\circ$ & $\circ$ & 0 \\
\hline Industria & $\circ$ & $\circ$ & $\circ$ & $\circ$ \\
\hline Otros usos & $\circ$ & $\circ$ & $\circ$ & $\circ$ \\
\hline NS & $\circ$ & $\circ$ & $\circ$ & $\circ$ \\
NC & $\circ$ & $\circ$ & $\circ$ & $\circ$
\end{tabular}


P.4. Del siguiente conjunto de medidas relacionadas con la gestión del agua, ¿cuál considera Ud. que sería la más adecuada para su Cuenca/Demarcación? ¿y la segunda? SOLO UNA RESPUESTA POR

COLUMNA.

$1^{\mathrm{a}}$ Medida $\quad 2^{\mathrm{a}}$ Medida

\begin{tabular}{lcc}
\hline $\begin{array}{l}\text { Mejorar regadios para que } \\
\text { consuman menos }\end{array}$ & 0 & 0 \\
\hline Construir más pantanos & 0 & 0 \\
\hline $\begin{array}{l}\text { Trasvasar agua de otras } \\
\text { regiones }\end{array}$ & 0 & 0 \\
\hline Ahorrar agua en los hogares & 0 & 0 \\
\hline Aumentar el precio del agua & 0 & 0 \\
\hline Disminuir el agua para regadios & 0 & 0 \\
\hline $\begin{array}{l}\text { Aprovechar agua de mar } \\
\text { (plantas desaladoras) }\end{array}$ & 0 & 0 \\
\hline $\begin{array}{l}\text { Reutilizar aguas residuales para } \\
\text { otros usos }\end{array}$ & 0 & 0 \\
\hline Hacer más pozos & 0 & 0 \\
\hline NS & 0 & 0 \\
\hline NC & 0 & 0 \\
\hline
\end{tabular}


P.5. Seguin su opinión, y centrándonos en las sequias, zcuál es el grado de importancia de las siguientes medidas destinadas a evitar los efectos de las futuras sequias en su Cuenca/Demarcación? *

\begin{tabular}{|c|c|c|c|c|c|c|}
\hline & $\begin{array}{c}\text { Muy } \\
\text { importante }\end{array}$ & $\begin{array}{l}\text { Bastante } \\
\text { importante }\end{array}$ & $\begin{array}{c}\text { Poco } \\
\text { importante }\end{array}$ & $\begin{array}{c}\text { Nada } \\
\text { importante }\end{array}$ & N5 & NC \\
\hline $\begin{array}{l}\text { Disminuir dolaciones de } \\
\text { riego }\end{array}$ & o & o & $\circ$ & $\circ$ & o & - \\
\hline $\begin{array}{l}\text { Construir emitakes/thalsas de } \\
\text { regulaciōn }\end{array}$ & o & 0 & $\circ$ & $\circ$ & 0 & o \\
\hline Utifizar agua reutifirada & o & o & $\circ$ & o & o & $\circ$ \\
\hline Utilizar agua desalada & 0 & 0 & o & 0 & 0 & 0 \\
\hline $\begin{array}{l}\text { Trasvasar agua de otras } \\
\text { cuencas }\end{array}$ & o & o & $\circ$ & o & o & o \\
\hline $\begin{array}{l}\text { Mejorar la gestiön de aguas } \\
\text { subterrảneas }\end{array}$ & $\circ$ & o & $\circ$ & o & o & o \\
\hline $\begin{array}{l}\text { Controlar las extracciones } \\
\text { ilegales }\end{array}$ & o & o & $\circ$ & o & o & $\circ$ \\
\hline Modernizar regadios & o & o & o & o & o & o \\
\hline Aumentar el precio del agua & o & o & $\circ$ & $\circ$ & o & o \\
\hline $\begin{array}{l}\text { Introducir condiciones de uso } \\
\text { mass eficiente del agua para } \\
\text { recibit subvenciones agrarias }\end{array}$ & 0 & o & 0 & o & o & o \\
\hline $\begin{array}{l}\text { Mdaptar cultivos a las } \\
\text { condiciones climáticas }\end{array}$ & o & o & $\circ$ & o & o & o \\
\hline Abandonar la agricullura & o & o & 0 & o & 0 & o \\
\hline $\begin{array}{l}\text { Realizar un plan de } \\
\text { recorversiön del regadio }\end{array}$ & $\circ$ & 0 & $\circ$ & 0 & o & o \\
\hline $\begin{array}{l}\text { Revisar y actualizar } \\
\text { concesiones }\end{array}$ & o & o & $\circ$ & o & 0 & o \\
\hline $\begin{array}{l}\text { Ceder derechos de agua a } \\
\text { cambio de compensaciones } \\
\text { econximicas }\end{array}$ & o & o & $\circ$ & o & o & o \\
\hline $\begin{array}{l}\text { Mejorar la infarmaciōnn } \\
\text { formaciōn y educaciôn sobre } \\
\text { sequäs }\end{array}$ & o & o & $\circ$ & o & 0 & 0 \\
\hline $\begin{array}{l}\text { Condicionar el desarrollo } \\
\text { urtarisitico al agua disponible }\end{array}$ & $\circ$ & o & $\circ$ & o & o & o \\
\hline $\begin{array}{l}\text { Condicionar la ampliacik̄n de } \\
\text { superficie regada al agua } \\
\text { disporible }\end{array}$ & $\circ$ & o & $\circ$ & o & o & o \\
\hline Crear un sistema de seguros & o & o & $\circ$ & $\circ$ & o & o \\
\hline
\end{tabular}


P6. ¿Podria decirme qué grado de confianza le merece las siguientes instituciones? *

Mucha Bastante Alguna Poca Ninguna confianza confianza confianza confianza confianza

\begin{tabular}{|c|c|c|c|c|c|c|c|}
\hline Unión Europea & 0 & 0 & 0 & 0 & 0 & 0 & 0 \\
\hline Gobierno España & 0 & O & 0 & 0 & 0 & 0 & O \\
\hline Gobierno regional & 0 & O & 0 & 0 & 0 & 0 & O \\
\hline Ayuntamientos & 0 & O & 0 & 0 & 0 & 0 & O \\
\hline Organizaciones agrarias & 0 & 0 & 0 & 0 & 0 & 0 & O \\
\hline Comunidad científica & 0 & O & 0 & 0 & 0 & 0 & O \\
\hline Organizaciones ecologistas & 0 & 0 & 0 & O & O & O & O \\
\hline Medios de comunicación & 0 & O & 0 & 0 & 0 & $\mathrm{O}$ & 0 \\
\hline
\end{tabular}

Por favor conteste las siguientes preguntas sólo con fines de clasificación de las respuestas:

D1. Sexo *

○ Hombre

$\circ$ Mujer

D2. Edad *

D3. Nivel educativo

- Estudios primarios

- Estudios medios

- Estudios superiores

D4.1. Municipio de residencia *

D4.2. Código postal * 
D5. ¿Pertenece Ud. a alguno de los siguientes colectivos? Puede marcar más de una respuesta.

$\square$ Empleado de la Administración Pública

$\square$ Estudiante

$\square$ Colaborador de una ONG o colectivo en defensa del medio ambiente

$\square$ Miembro de un colectivo agrario (sindicato, cooperativa, comunidad de regantes, etc.)

$\square$ Empleado empresa/consultoría relacionada con el agua

$\square$ Comunidad cientifica

\section{D6. Su interés en conocer más aspectos sobre agua es fundamentalmente:}

- Laboral

○ Académico

Personal

D7.1. Para contestar este cuestionario, ¿ ¿ha utilizado la información disponible en este portal?

○ Si

○ No

\section{D7.2. Si contesta Sí en la anterior pregunta: ¿Para qué pregunta utilizó la información?}

- Principales problemas del agua en su cuenca

- Opinión sobre el cambio climático

- Distribución del consumo de agua entre sectores

- Principales medidas para mejorar la gestión del agua

- Principales medidas para evitar los efectos de futuras sequías

- Grado de confianza en distintas instituciones 


\section{Observatorio Ciudadano de la Sequía}

Citizen Observatory of Drought

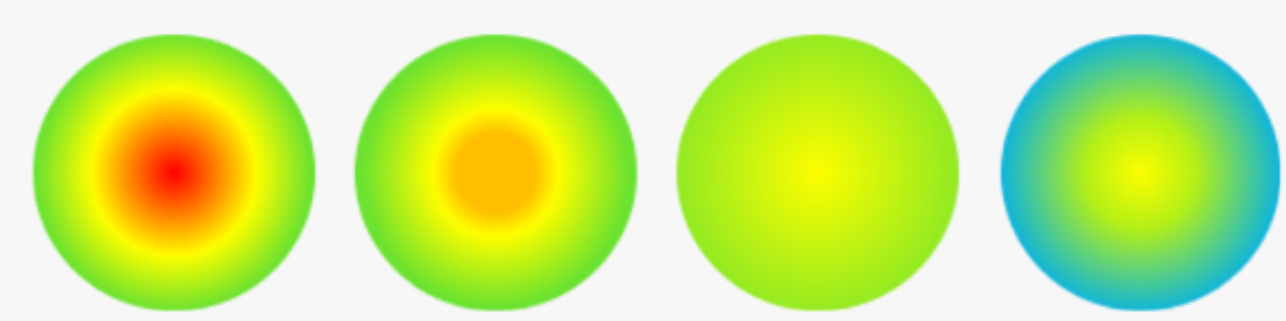

2021 